\title{
AN ANALYSIS OF TAX BUOYANCY IN TURKEY
}

\section{DOI: 10.17261/Pressacademia.201519777}

\section{Sevda Akar', Ozge Uysal Sahin²}

1Balıkesir University. sevda@balikesir.edu.tr

${ }^{2}$ Canakkale University. uysal83@gmail.com

\section{Keywords}

Tax buoyancy, Turkey, cointegration, error correction model.

JEL Classification E62, H21, H29

\begin{abstract}
Tax Buoyancy which measures the effectiveness of tax system is the sum of the reactions in tax revenues (sum of the changes in tax revenues) to the changes in national income and the discretionary changes. In this study, the buoyancy of tax system in Turkey is analyzed with monthly data of centralized executive budget tax revenues and industrial production index (IPI) for the period of 2005 January to 2014 June by means of cointegration and error correction models. According to the results of the analysis, the tax system isn't a good stabilizator in the short run, but the growth increment affects fiscal sustainability positively in the long run.
\end{abstract}

\section{TÜRKIYE'DE VERGI CANLILIĞININ ANALIZi}

\section{Anahtar Kelimeler \\ Vergi canlılığı, Türkiye, eşbütünleşme, hata düzeltme modeli.}

JEL Sınıflandırması

E62, H21, H29

\section{ÖZET}

Vergi sisteminin etkinliğini ölçen vergi canlılığı, vergi gelirlerinin milli gelirdeki değişime ve ihtiyari düzenlemelere verdiği tepkilerin (gösterdiği değişimlerin) toplamıdır. Bu çalışmada Ocak 2005 - Haziran 2014 dönemi arasında merkezi yönetim bütçe vergi gelirleri ve sanayi üretim endeksi (SUE) değişkenlerine ait aylık veriler kullanılarak, Türkiye'de vergi sisteminin canlılığı eşbütünleşme ve hata düzeltme modeli ile analiz edilmeye çalışılmıştır. Çalışmanın ampirik sonuçlarına göre, kısa dönemde vergi sistemi iyi bir otomatik istikrarlandırıcı olmadığını ancak, uzun dönemde büyüme artışının mali sürdürülebilirliği olumlu etkilediğini göstermektedir.

\section{GiRiş}

İktisadi sıkıntıların ortaya çıkması ve dengelerin bozulmasının en önemli nedenlerinden biri kamu finansman açıklarıdır. Günümüzde birçok ülke, kamu finansman açıklarını ya vergi gelirlerini artırarak ya da harcamalarını azaltarak kapatmaya çalışmaktadır. Bu açıdan, vergi sisteminin etkinliği büyük önem arz etmektedir. Vergi sisteminin etkinliğini ölçmede, iki önemli ölçüt kullanılmaktadır. Bunlardan ilki vergi esnekliği, diğer ise vergi canlılı̆ıdır. Vergi esnekliği, gayri safi yurt içi hasıla (GSYH) ile vergi gelirleri arasındaki ilişkiyi ifade etmekte ve vergi gelirlerinin $\mathrm{GSYH}^{\prime}$ da meydana gelen değişimlere verdiği otomatik tepki olarak tanımlanmaktadır. 
Vergi canlılığı ise hem milli gelirde meydana gelen değişimlere hem de ihtiyari değişimlere (vergi oran ve tabanındaki değişmeler, vergi yönetiminin etkinliğindeki değişimler, yeni vergilerin konması, bazı vergilerin kaldırılması gibi) verdiği tepkilerin toplamını ifade etmektedir (Twerefou vd, 2010: 36).

Sonuç olarak, vergi gelirleri, GSYH'daki değişikliklerden etkilenerek otomatik olarak değişebileceği gibi yasama ve yürütme tarafından yapılan değişiklikler ve düzenlemelerle de değişebilmektedir (Rajaraman vd., 2005:1-3).

Bu nedenle verge sisteminde yapılan tüm değişikliklerin yansımasını görmek açısından vergi canlılı̆ı̆ kavramı ön plana çıkmaktadır. Özellikle bütçe kısıtı içerisinde hareket etmeye çalışan birçok gelişmekte olan ülke için vergi canlılığının büyüklüğü daha da önem kazanmaktadır. Çünkü, vergi canlılığı değeri 1 birimin üzerine çıktığında, vergi gelirleri GSYH'dan daha fazla artmakta ve kamu açıkları oranında azalmalara neden olmaktadır. Diğer bir deyişle, kamu finansman açıklarında vergilere başvurma isteği artmakta ve kolaylaşmaktadır.

Literatürde ülkelerdeki vergi canlıı̆̆ını ölçmeye yönelik bir çok çalışma bulunmaktadır. Ancak Türkiye'de bu konuda yapılan çalışmalar sınırlı sayıdadır. Bu nedenle, çalışmanın Türkiye'de vergi canlılı̆ııı hem kısa hemde uzun dönem açısından ele alması sebebiyle literature katkı yapması beklenmektedir.

Çalışma şu şekilde organize edilmiştir. Birinci bölümde vergi canlılı̆ı tanımlanmış ve bu tanımı anlamaya yönelik kavramsal çerçeve verilmiştir. İkinci bölümde, vergi canlılığına yönelik dünyada ve Türkiye'de yapılmış çalışmalardan bahsedilmiştir. Üçüncü bölümde merkezi yönetim bütçe vergi gelirlerinin GSYH ile ilişkisi eşbütünleşme analizi ve hata düzeltme modeli ile analiz edilmiştir. Dördüncü bölümde, ampirik bulgulara yer verilmiş ve beşinci bölümde çalışma sonuç bölümüyle bitirilmiştir.

\section{KARAMSAL ÇERÇEVE}

Vergi canlılığı, vergi gelirlerindeki değişimin milli gelirdeki değişikliklere olan duyarlılı̆ını ifade etmektedir. Bu tanımda görüldüğü gibi vergi canlılı̆ı ile vergi esnekliği kavramları birbirine benzerdir. Ancak bu iki kavram arasında çok önemli bir fark bulunmaktadır. Vergi canlıı̆̆ı kavramı idari düzenlemeleri de içermektedir. İdari düzenleme ile kastedilen otomatik etkiler dışında kalan ve yürütme ile yasama erkinin yapmış olduğu düzenlemeleri içine almaktadır (Ertürk Atabey, vd., 2009: 110). Daha açık bir ifadeyle, vergi esnekliği GSYH'daki değişimlere karşı vergi gelirlerinin gösterdiği değişimdir ki buna "otomatik" değişim de denilmektedir. Vergi canlılığı ise, vergi gelirlerinin yalnızca GSYH'daki değişimlere değil; vergi oranları, vergi tabanları, regülasyonlar ve yönetimin etkinliğindeki değişimler gibi intiyari değişimlere karşı gösterdiği değiş̧imi de ifade etmektedir. (Mukarram, 2001: 75-76). Buradan anlaşılacağı üzere, vergi canlılı̆ı, vergi esnekliğini de kapsayan daha geniş bir tanımdır. Vergi esnekliği sadece milli gelirdeki değişmeler karşııında vergi gelirlerinde otomatik değişmeleri ifade ederken; vergi canlılı̆ı vergi gelirlerindeki otomatik değişmelerle birlikte idarece alınan önlemler sonucunda ortaya çıkan vergi geliri değişmelerini yansıtmaktadır (Durmuş, 2003: 215-216). Denebilir ki, devlet tarafından alınan önlemlerle ortaya çıkan vergi geliri değişimlerinin vergi esnekliğine eklenmesi durumunda vergi canlılı̆ı tanımına ulaşılmaktadır (Haughton, 1998:1-3). 
Vergi canlıı̆̆ıyla, milli gelirdeki değişimler ile vergi sisteminde yapılan ihtiyari değişimler sonucunda vergi gelirinde ne kadarlık bir değişim yaşandığı, vergilerin söz konusu değişimlerden ne kadar etkilendiği ölçülmektedir (Indraratna, 2003).

Vergi sisteminin etkinliğini ölçmede ve gelecek vergi politikasını tasarlamada belirleyici unsurlar olan vergi esnekliği ve vergi canlılığı tüm vergi sistemi için hesaplanabileceği gibi gelir vergisi ve tüketim vergisi gibi tek tek vergiler için de hesaplanabilmektedir. Vergi tarifesi açısından genellikle azalan oranlı ve özel vergiler düşük esneklik ve canlılık göstermektedir (Skeete vd., 2003: 134). Bununla beraber, artan oranlı ve genel yapıdaki vergiler daha yüksek esnekliğe ve canlılığa işaret etmektedir.

Vergi esnekliğini formülü denklem (1)'de gösterilmektedir. Bu denkleme göre, vergi geliri $T$, GSYH ise $Y$ ile tanımlanmıştır:

$$
E_{T Y}=\frac{\Delta T}{\Delta Y}
$$

Vergi gelirinin GSYH'ya oranı, birden daha küçük bir değer alırsa, GSYH büyümesine karşılık gelen gecikmeli gelir büyümesini ifade etmektedir. Bu durumda esnek olmayan bir vergi yapısını göstermektedir. Vergi gelirinin GSYH büyümesine benzer olması, yani 1'e eşit olması birim esneklik bir yapıya işaret etmektedir. Vergi gelirinin GSYH'ya oranının birden daha büyük bir değer alması ise, vergi gelirlerindeki büyümenin GSYH büyümesini aştığını ve vergi sisteminin esnek bir yapıda olduğunu göstermektedir. Ayrıca, belli bir vergi için marjinal vergi oranı ortalama vergi oranına eşit ya da ondan küçük olduğunda esnek olmayan vergilemeden bahsedilmektedir. Ancak, marjinal vergi oranı ortalama vergi oranını aşarsa, esnek bir vergilemeden söz edilebilir. Esnek bir vergi sisteminin varlığı halinde ise, vergilerin otomatik stabilizatörlük özellikleri ortaya çıkmakta ve müdahaleye gerek kalmaksızın ekonominin duruma göre kendiliğinden ayarlandığı ifade edilmektedir.

Bir vergi sisteminde vergi canlılığı ise genellikle toplam vergi gelirlerinin milli gelir içindeki oransal değişimi ile ölçülmekte ve denklem (2)'deki gibi gösterilmektedir (Twerefeou, vd., 2010: 46);

$$
B_{T Y}=\frac{\Delta T / T}{\Delta Y / Y} \text { ve ya } B_{T Y}=\frac{\Delta T}{\Delta Y} * \frac{Y}{T}
$$

Toplam vergi canlılı̆̆, vergi sayısı $n$ ile gösterilirse bireysel vergi canlılığı toplamları denklem (3) gibi ayrıştırılabilmektedir;

$$
B_{T Y}=\frac{T_{1}}{T_{t}} B_{T_{1} Y}+\frac{T_{2}}{T_{t}} B_{T_{2} Y}+\cdots+\frac{T_{n}}{T_{t}} B_{T_{n} Y}
$$

Denklem (1, 2 ve 3)'ten hareketle, vergi canlılığın 1'den küçük olması durumunda (vergi gelirindeki büyümenin GSYH'daki büyümeden daha az olduğunda) vergi esnekliğinin düşük ve ihtiyari değişimlerin etkinsiz olduğu söylenmektedir. Vergi canlılığının 1 olması durumunda, GSYH ile vergi geliri artışlarının birbiriyle uyumlu olduğu ifade edilmektedir. Diğer bir deyişle, GSYH \%1 büyüdüğünde vergi gelirleri de \%1 büyümektedir. Birden daha büyük bir canlılık değeri ise, vergi gelirindeki büyümenin daha fazla olduğunu göstermektedir. Böyle bir durum ihtiyari değişimlerin vergi sisteminin cevap verebilirliğini arttırmaktadır. Vergi sisteminin değişimlere cevap verebilirliğinin derecesini tespit etmek, hükümetlerin mali sistemi düzeltmek için daha doğru tahminler yapmasına imkan sağlamaktadır (Skeete vd., 2003: 134; Mitchell ve Andrews, 1999: 186). 
Bununla birlikte, ekonomik büyümenin mali açıkların kapatılmasında ne kadar etkili olduğunun anlaşılmasını mümkün kılmaktadır. Bu kapsamda, vergi canlılığının büyüklüğü vergi sistemi açısından büyük önem arz etmektedir.

Eğer vergi canlılı̆ı vergi esnekliğinden büyük ise ihtiyari vergi önlemlerinin vergi gelirlerini artırıcı etkisinin milli gelirin yarattığı otomatik arttırma etkisinden daha fazla olduğu söylenebilir. Diğer bir ifadeyle, yapılan idari düzenlemeler vergi gelirlerini pozitif yönde etkilemektedir. Vergi canlılığı vergi esnekliğine eşit ise ihtiyari önlemlerin vergi gelirleri üzerinde çok az ya da hiçbir etkisi olmadığı ileri sürülebilir. Vergi canlılığı vergi esnekliğinden küçük olduğu durumlarda, ihtiyari vergi önlemlerinin vergi gelirlerinde azalma yaratması beklenmektedir. Bununla birlikte, idari düzenlemeler her zaman vergi gelirlerini artırıcı bir etki yaratmayabilir. Vergi gelirlerinin azalmasına neden olacak düzenlemeler olduğunda vergi canlılığı vergi esnekliğinden daha düşük seviyede kalmaktadır. Bu durumun temel nedeni olarak idari düzenlemelerin negatif etkiye sahip olması gösterilmektedir (Ertürk Atabey, vd., 2009: 112).

Mansfield (1972) ile Howard vd., (2010) yüksek vergi esneklikleri ve vergi canlılıklarının gelişmekte olan ülkeler için önemli olduğunu vurgulamaktadırlar. Çünkü hükümetler vergi oranları ve vergi tabanlarında sık sık artış yapma gereği duymadan bir harcama politikası izleyebilmektedir. Bu durum özellikle, toplumsal sakıncalar yaratacağı endişesiyle vergileri arttırmaya yönelik siyasi irade göstermeyen hükümetler için finansman ihtiyacını gidermede büyük önem arz etmektedir.

Vergi canlılığı, beklenmedik gelir artışlarının geçmişten günümüze değin vergi açısından tepkisini ölçmektedir. Bunun yanında, ilgili mali kurallar ile mali durum ve gelecekteki mali zorluklar hakkında gelişmiş bilgi sağlamakta ve maliye politikalarında geçmişte yapılan hataların tekrarından kaçınılmasına yardımcı olmaktadır (Joumard ve Andre, 2008: 5). Vergi canlılı̆ı, vergi tabanının etkisine göre zamanla değişebilmektedir. Bunun temel nedeni ise, gelişmekte olan bir ülkede ekonomi büyüdükçe, daha çok insanın ve daha çok firmanın daha fazla gelire sahip olması ve böylece daha fazla vergi ödemeye razı olmalarından kaynaklanmaktadır. Zamanla insanlar ve firmalar zenginleştikçe, vergi tabanları GSYH'dan daha hızlı büyümektedir. Bu durumda vergi canlılığı tahminlerini yukarılara çekmektedir. Yine, gelişmekte olan bir ülke sanayileşmesini giderek arttırdıkça, hükümet de daha iyi idari hizmetler sunmakta ve daha fazla vergi tahsilatı sağlayan vergi yasaları yaparak vergi sistemini iyileştirmeye çalışmaktadır. Vergi tahsilatı da arttıkça, vergi canlılı̆ının yükselme potansiyeli artmaktadır. Benzer şekilde, vergi sisteminde yapılan vergi oranlarını arttırma gibi değişimler de vergi canlılığı artışına sebep olabilmektedir (Kasipillai ve Mustafa, 2000: 80).

\section{VERGi CANLILIĞINA İLişKIN LITERATÜR}

Literatürde vergi canlılığına ilişkin birçok ülkeyi kapsayan ve farklı ekonometrik modeller kullanılarak yapılmış çok sayıda çalışma bulunmaktadır. Bu çalışmaların başında, Mansfield (1972)'in 1962-1970 dönemi için Paraguay’ın vergi sisteminin esnekliği ve canlılığını çifte logaritmik yöntemle analiz ettiği çalışma gelmektedir. Bu sayede Mansfield (1972), gelirlerdeki büyümeyi tespit etmeyi amaçlamıştır. Sonuçta, söz konusu dönemde vergi oranlarındaki güçlü artışın daha çok, vergi sistemindeki ihtiyari (isteğe bağı) değişikliklere bağlı olduğuna ulaşmıştır. 
Pakistan'da gelirlerin verimliliğini tahmin ederek mali sistemin performansını ölçmeyi hedefleyen Gillani (1986) ise 1971-72'den 1982-83'e kadar olan dönemde kısa ve uzun dönemde Pakistan federal vergi sisteminin canlılı̆ını Divisia Endeksi Yöntemi ve Oransal Ayarlama Yöntemiyle (Proportional Adjustment Method) analiz etmiştir.

Analiz sonuçları da göstermiştir ki, birkaç istisna hariç, farklı vergi türlerindeki artışların neredeyse tamamı içsel faktörlerden kaynaklanmaktadır ve ihtiyari değişikliklere bağı değildir. Yine, Akbar ve Ahmed (1997)'de 1973-1990 dönemi için Pakistan'da Federal Hükümetin vergi ve harcamalarının esnekliğini ve canlılığını Prest metodolojisiyle analiz etmiştir. Özellikle gümrük vergisi ve tüketim vergisinin düşük esnekliğe ve canlılığa sahip olmasından dolayı vergiler için tümden esnekliğin ve canlılığın düşük olduğu sonucuna ulaşmışlardır. Gelir vergileri ve satış vergileri için esneklik ve canlılık görece daha yüksek tahmin edilmiştir. Pakistan'da vergi esnekliğini ve canlılığını ölçen bir diğer çalışma Mukarram (2001) tarafından 1981-2001 dönemi için Zincir İndeksleme Tekniği (Chain Indexing Technique) kullanılarak, yapılmıştır. Analizler neticesinde, doğrudan vergilerin tüketim vergilerine göre esneklik ve canlılık oranlarının daha yüksek olduğu görülmüştür. Ayrıca, tüm vergiler için canlılık tahminleri esneklik tahminlerine göre daha yüksek olduğu bulunmuştur. Doğrudan vergiler ve satış vergileri için ise, canlılık katsayıları 1'den büyüktür. Gelirlerdeki artış daha çok vergi oranlarındaki artıştan ve vergi tabanlarındaki genişlemeden kaynaklanmaktadır. Bu bağlamda, Mukarram (2001) vergi reformlarının tüm vergi sistemini iyileştirdiğini iddia etmektedir. Fakat Mukarram (2001)'ın aksine Bilquees (2004) Divisia İndeksi method ile 1974/75 - 2003/04 dönemi için Pakistan'da vergi esnekliklerini ve canlılıklarını ölçtüğü çalışmasında, 1'in altında tahmin edilen katsayılar sonucunda vergi reformlarının Pakistan'da önemli bir gelir artışı yaratmadığı sonucuna varmıştır. Rasheed (2006) ise çalışmasında Pakistan'daki vergi canlılı̆̆ını nelerin etkilediğini tespit etmek için bir analiz yapmıştır. Bu çalışma ile 1975-2002 yılları arasında Pakistan' da doğrudan, dolaylı ve toplam vergiler üzerinde Sabit Kur Yapısı, Oransal Ayarlar, Divisia Indeksi ve ekonometrik yöntemler kullanılarak vergi canlılı̆ı tahmin edilmiştir. Ayrıca, vergi canlılı̆̆ tahminlerinin çeşitli bağımsı makroekonomik değişkenlerle ilişkisi incelenmiştir. Sonuçta, vergi kaçırma faktörünün etkisiz olduğu; vergi gelirleri ile büyüme, yatırım, kredi, kamu borçları ve enflasyon arasında bir ilişki bulunduğu tespit edilmiştir. Çalışmada ayrıca, Pakistan'ın vergi rejiminin zayıf olduğu ve iyileştirilmesi gerektiği vurgulanmıştır.

Chowdhury ve Hossain, (1988) ise Bangladeş için 1975/76 - 1984/85 dönemlerinde öne çıkan vergi türlerine yönelik esneklikleri ve canlılıkları tahmin etmeye çalışmışlardır. Regresyon tekniği ve Oransal Ayarlama Yöntemini kullandıkları çalışmada yerel mal ve hizmetlerden alınan vergiler ile bileşeni olan tüketim vergileri hariç olmak üzere diğer tüm vergilerde vergi canlıı̆̆ını 1'den büyük bulmuşlardır. En yüksek canlılık 1,11 ile ithalattan alınan vergilerde iken; en düşük canlılık 0,90 ile yerel mal ve hizmetlerden alınan vergilerde olduğu tespit edilmiştir. Tüm vergi sistemi için ise ortalama canlılık 1,03'tür. Benzer şekilde, Yousuf ve Huq (2013)'da Bangladeş için 1970/79 - 2010/11 dönemini kapsayacak biçimde vergilerin ve vergi bileşenlerinin esnekliğini ve canlılı̆ını Johansen eşbütünleşme Tekniği ve Hata Düzeltme Modelini kullanarak analiz etmiştir. Satış Vergisi ve KDV'ye göre doğrudan vergiler için esneklik ve canlılık daha yüksek çıkmıştır. Ayrıca, canlılığın tüm vergiler için de esnekliğe göre daha yüksek düzeyde olduğu görülmüştür. Bu durum gelirlerdeki büyümenin büyük ölçüde ihtiyari değişimlere bağlı olduğunu göstermektedir. 
Osoro (1993) ise 1979-1989 yıllarını kapsayan dönem için Tanzanya'da vergi reformlarının gelirlerin verimliliği üzerine etkilerini incelemiştir. Vergi canlılığını hesaplamak için çifte logaritmik yöntemi ve vergi esnekliğini hesaplamak için Oransal Ayarlama Yöntemini kullandığı çalışmasında tüm vergiler için esnekliği 0,76 ve canlılığı ise 1,06 olarak tahmin etmiştir.

Tanzanya'da vergi reformlarının vergi gelirlerini arttırmada başarısız olduğu sonucuna ulaşmıştır. Ahmed (1994) ise gelişmekte olan ülkeler için vergi gelirlerinin canlılığını (hem tüm vergiler hem de doğrudan ve dolaylı vergiler için) incelemiştir. Analizler sonucunda, öncelikle ithalat sektörü ve sanayi sektöründeki büyümenin gelişmekte olan ülkelerde vergilerdeki artışı pozitif yönde etkilediği görülmektedir. Bununla beraber, hizmetler ve tarım gibi diğer sektörlerdeki etkiler yetersiz kalmaktadır. Ayrıca monetizasyondaki artış da vergilerdeki büyümeyi kolaylaştırmaktadır.

Kusi (1998) 1970-1993 dönemi için Gana'da vergi reformu ve gelir verimliliğini analiz etmiştir. Sonuçlar göstermektedir ki, reform öncesi dönemde (1970 - 1982) vergi canlılığı 0,72 ve vergi esnekliği ise 0,71 'tir. Vergi sonrası dönemde (1983-1993) ise vergi canlılı̆ı 1,29'a ve vergi esnekliği 1,22'ye yükselmiştir. Vergi reformunun Gana'da vergi gelirlerinin verimliliğini 1983-1993 döneminde önemli ölçüde arttırdığı anlaşılmaktadır. Twerefou vd., (2010), Gana'da 1970-2007 dönemi için kukla değişken tekniği kullanarak ihtiyari vergi önlemlerinin etkileri açısından Gana vergi sisteminin esnekliğini tahmin etmiştir. Elde edilen bulgulara göre, Gana'da uzun dönemde tüm vergi sistemi esnek ve canlı iken; kısa dönemde tam tersi geçerlidir. Mitchell ve Andrews (1999) başlıca Doğu Karayipler Para Birliği ülkelerinde (Dominik, St.Luçiya, Antigua ve Barbuda) vergi gelirlerinin canlılığını hesaplamıştır. 1980 'lerde her birinde vergi sisteminin oldukça canlı olduğu görülmüştür. Fakat 1990'lara gelindiğinde bu canlılık toplam vergiler için giderek azalmıştır. Bu durum ülkelerin koloni olmaktan kurtulup bağımsız bir devlet olmalarıyla beraber yaşanan sosyopolitik değişime bağlanmaktadır. Yine, Hamlet (2013)'de bu ülkelerde 1980-2010 dönemi için vergi canlılığını analiz etmiştir. Çalışma sonuçları, söz konusu ülkelerde vergi geliri yapılarının canlı olduğunu göstermektedir. Ayrıca, bu ülkelerde ihtiyari önlemlere oldukça başvurulduğu görülmektedir.

Wawire (2000) Kenya'nın vergi sisteminin canlıı̆̆ını ve esnekliğini toplam GSYH'yı kullanarak tahmin etmeye çalışmış ve sonuçta, vergi sisteminin gelirleri arttırmada yetersiz olduğuna ulaşmıştır. Benzer şekilde, Mawia ve Nzomoi (2013) de Kenya için 1999/2000 201/2011 dönemini esas alarak zaman serisi yaklaşımıyla farklı vergi türleri ve toplam vergilerin vergi canlıığını hesaplamıştır. Analiz sonucunda, tüketim vergileri hariç bireysel vergiler canlı değilken, toplam vergilerin 2,58 oranında canlı olduğu tespit edilmiştir. Vergi canlılıkları 1'den büyük olduğu zamanlarda vergi tabanlarının iktisadi değişimlere daha iyi tepki verdiği görülmüştür. Samwel ve Isaac (2012) Kenya için vergi canlılığı konusunda Mawia ve Nzomoi (2013)'nun tam tersi sonuçlara ulaşmıştır. Kenya'da vergi sisteminin ve bileşenlerinin esnekliğinin ve canlılığının 1986-2009 dönemi için en küçük kareler yöntemi kullanarak hesaplandığı çalışmada, Kenya'nın vergi sisteminin ne gelir esnek ne de canlı olduğu görülmüştür. Tüm vergi bileşenleri de inelastiktir. Bu dönemdeki gelir vergisi ve tüketim vergilerinin canlılığı ise 1 'dir. İthalat vergileri en canlı vergi bileşeniyken, satış vergileri en az canlı vergi bileşenidir. Bu nedenle çalışmada, vergilerin modernizasyonunun yeniden gözden geçirilerek vergi yönetim mekanizmalarının güçlendirilmesi önerilmektedir. 
Kasipillai ve Mustafa (2000) ise Malezya'da doğrudan ve dolaylı vergilerin canlılıklarını 1961-1998 dönemi için analiz ettikleri çalışmalarında, Box-Cox metodunu kullanmışlardır. Analiz sonucunda, hem doğrudan hem de dolaylı vergiler için canlıkların giderek azaldığını görmüşler ve bunun da vergi sisteminin etkinsizliğini yansıttığını ifade etmişlerdir.

Skeete vd., (2003) 1977-1999 yıllarını kapsayan dönemde Barbados'un mali sisteminin performansını gelir verimliliği tahminlerine dayalı olarak incelemişlerdir. Bu açıdan, vergi esnekliklerini ve canlııklarını hesaplamak için hata düzeltme modelini kullandıkları çalışmalarında, toplam vergi gelirleri ile doğrudan ve dolaylı vergi gelirleri için kısa ve uzun dönemdeki esneklikleri ve canlılıkları tahmin etmişlerdir. Vergi esnekliklerinin kısa dönemde GSYH'daki değişimlere daha çok cevap verdiği, ihtiyari değişimlerin ise vergi sisteminde etkili olduğu ve canlılık katsayılarının esneklik katsayılarından daha büyük olduğu sonucuna ulaşmışlardır. Mishra (2005) ise Cakarta'da 1995/96-2004/05 dönemi için satış vergisinin canlılığını regresyon modelini kullanarak hesaplamıştır. Bu vergilerin canlıı̆̆ının 1'den büyük olduğu görülmüştür ki, bu durumda satış vergisi gelirlerinin GSYH'dan daha hızlı büyüdüğünü ifade etmektedir. Rajaraman, vd., (2005) Hindistan eyaletlerinde vergi canlıı̆ı̆ını 1980/81 - 2003/04 dönemini kapsayacak biçimde analiz etmişlerdir. Vergi gelirlerinde merkezden gelen vergiler dikkate alınmamış, ancak GSYH değişkeni kullanıımıştır. Sonuçta, 1990'ların sonundaki kırılma ile canlılığın yönünün pozitife döndüğü görülmüştür. Timsina (2007)'da zaman serisi yaklaşımılya Nepal'da 19752005 dönemi için vergilerin esnekliğini ve canlılığını farklı vergi türlerini dikkate alarak tahmin etmiştir. Analizler sonucunda, hem vergi canlılı̆ının hem de vergi esnekliğinin inelastik bir yapı olduğu görülmüştür. Upender (2008)'de yine Hindistan için durağan zaman serileriyle ilişkilendirdiği çifte logaritmik regresyon modelini kullanarak, vergi reformu öncesi ve sonrası dönemde vergi canlııı̆ını incelemiştir. Çalışmada 1950/51 2004/05 dönemi esas alınmıştır. Çalışma sonuçlarına göre, vergi reformu öncesi vergi canlılığının 1'in biraz üzerinde olduğu; vergi reformu sonrası dönemde vergi canlılı̆ının $1^{\prime}$ in altında kaldığı görülmüştür. Bu durumun daha çok vergi gelirlerinin GSYH'ya olan oranının GSYH'daki değişimlere bağlı olarak azalıp artmasıyla ilgili olduğu ifade edilmiştir.

Joumard ve Andre (2008), 2005-2007 döneminde OECD ülkelerinde uygulanan maliye politikalarındaki iyileştirmelerin vergi gelirlerine etkisini analiz etmiştir. Bu etkiler kamu harcamaları için artışlar ve vergi indirimlerine yönelik baskılar olarak görülmüştür. Geçmişte bu tür taleplere yanıt olarak bütçe pozisyonlarının zayıflatıldığı belirtilmiş ve analizde beklenmedik gelir artışlarıyla vergi canlılığına yönelik geçmiş tepkiler incelenmiştir. Ahmed ve Mohammed (2010)'da çalışmasında gelişmekte olan ülkelerde vergi canlıı̆ının belirleyicileri üzerine odaklanmıştır. 1981-2006 döneminin ele alındığı çalışmanın analiz sonuçlarına göre; ithalat, imalat sanayi ve hizmet sektörleri ile monetizasyon ve bütçe açığı vergi canlılığını pozitif yönde; yardımların artış oranı ise negatif yönde etkilediği görülmüştür. Tarım sektörünün büyüme oranının ise vergi canlılığı üzerinde anlamlı bir etkide bulunmadığı sonucuna varılmışırı. Milwood (2011) ise Jamaika'da GSYH'daki büyümeyle vergi gelirlerindeki artı̧̧ arasındaki ilişkiyi ve vergilerin maliye politikasına tepkisini anlamaya çalışmıştır. Bu bağlamda, vergilerin esnekliğini ve canlıı̆ııı Mart 1998 - Aralık 2010 dönemi için Divisia Indeksini kullanarak hem toplam vergiler hem de vergi kalemleri bazında analiz etmiştir. Analiz sonucunda, ihtiyari değişimlerin vergi gelirlerindeki artışta etkili olduğu, fakat otomatik değişimlerin etkisinin 1 'den az olduğu tespit edilmiştir. 
Belinga vd., (2014) ise 34 OECD ülkesinde 1965-2012 yıllarını kapsayan dönem için kısa ve uzun dönem vergi canlılığını hata düzeltme modeli kullanarak belirlemişlerdir.

Çalışma sonucunda, öncelikle kısa dönemde OECD ülkelerinin birçoğu için vergi canlılı̆ının 1'e yakın olduğunu ve bu canlıı̆ı̆n 1980'den itibaren giderek artmaya başladığını görmüşlerdir. Bu durum vergi sisteminin giderek iyi bir otomatik istikrarlandırıcı olduğunu göstermektedir. Bununla beraber, 14 OECD ülkesinde uzun dönem vergi canlılığı 1'in üzerindeyken diğerlerinin de 1'e yakın olduğu tespit edilmiştir. Bu durum ise GSYH büyümesinin yapısal mali açıkları iyileştirmede etkili olacağının bir göstergesidir. Vergi bileşenlerine göre bakıldığında ise, kurumlar vergisinin en yüksek kısa dönem canlılığa sahip olmasıyla en iyi otomatik istikrarlandırıcı olduğu anlaşılmaktadır. Bu verginin uzun dönem canlılığı da yüksektir. Tüketim vergileri ve servet vergileri ise en düşük kısa ve uzun dönem canlılığa sahip olan vergilerdir. Bunun yanında, bireysel gelir vergilerinin kısa ve dönem canlılığı da 1980 'lerden sonra giderek azalmış ve ortalama olarak 1'in altına gerilemiştir.

Türkiye'de de vergi canlıı̆̆ıyla ilgili yapılmış birkaç çalışma bulunmaktadır. Bu çalışmalardan biri, Ertürk Atabey, Avşar ve Bulut (2009) tarafından yapılmıştır. Bu çalışma, Türkiye'de 1981-2006 dönemi toplam vergi gelirleri, kurumlar vergisi ve katma değer vergisi kalemleri için vergi canlıı̆ı̆ını ve vergi esnekliğini esas almaktadır. Çalışma sonucunda, teorik olarak beklentiler ile uygun olarak canlılık katsayıları pozitif değerler almıştır. Toplam vergi gelirleri hariç olmak üzere kurumlar vergisinde ve katma değer vergisinde canlılık katsayılarının esneklik katsayılarından büyük olduğu görülmüştür. Bununla beraber, tahmin edilen her üç canlılık katsayısı da 1 değerinden küçük olduğu için söz konusu vergilerin canlı olduğunu söylemek mümkün değildir.Türkiye ile ilgili bir diğer çalışma Şimşek (2013) tarafından yapılmıştır. Şimşek (2013) Türkiye'nin vergi esnekliği, vergi canlılığı ve vergi gayretini bölgesel panel veri yöntemi kullanılarak analiz etmiştir. Çalışmada 2004-2008 dönemi için 26 bölgeye ilişkin toplam vergi gelirleri ile kurumlar vergisi, gelir vergisi ve katma değer vergisi gelirleri esas alınmıştır. Bu çalışma, Türkiye'de tüm vergi türleri için vergi esnekliklerinin 1' in altında kaldığı diğer bir ifadeyle duyarlı olmadığını göstermiştir. Vergi canlılıkları için ise toplam vergi gelirleri ve kurumlar vergisi gelirlerinde kullanılan kukla değişkeninin vergi esnekliklerini artırdığı fakat buna rağmen vergi esnekliklerinin 1 ' in altında kaldığı görülmüştür.

\section{VERI VE METODOLOJi}

Bu çalışmada Ocak 2005 - Haziran 2014 dönemi arasında merkezi yönetim bütçe vergi gelirleri ve Sanayi Üretim Endeksi $(S U E)^{1}$ değişkenlerine ait aylık veriler kullanılmıştır. Merkezi yönetim bütçe vergi gelirleri değişkeni; gelir ve kazanç üzerinden alınan vergilerini, mülkiyet üzerinden alınan vergi gelirlerini, dahilde alınan mal ve hizmet vergilerini, uluslar arası ticaret ve muamelelerden alınan vergileri, damga vergisini, harçları ve diğer gelirleri kapsamaktadır. Veri setinin 2005 yılından itibaren ele alınmasının temel nedeni, 5018 sayılı yasanın 2003 yılında yürürlüğe girerek, merkezi yönetim bütçe vergi gelirleri kalemlerinin hesaplama yönetimini değiştirmesidir.

${ }^{1}$ Çalışmalarda Gayrı Safi Yurtiçi Hâsıla (GSYH) verileri daha çok kullanılmakla beraber, bu seri aylık frekansla ölçülmemektedir. Bu nedenle GSYH yerine, sanayi üretim endeksine ait aylık verileri kullanılmıştır. 
Çalışmada kullanılan veriler Türkiye Cumhuriyet Merkez Bankası Elektronik Veri Dağıtım Sisteminden (http://evds.tcmb.gov.tr/) alınmış ve Tramo-Seats yöntemi ile mevsimsellikten arındırılmıştır. Ayrıca kullanılan veriler reelleştirilmiş ve logaritması alınmıştır. Logaritması alınmış ve reelleştirilmiş değişkenlerden merkezi yönetim bütçe vergi gelirleri $\triangle L V \operatorname{erg} i$; SUE ise $\triangle L S U E$ olarak gösterilmiştir. Çalışmada yer alan serilerin özel istatistikleri Tablo 1'de belirtilmiştir. Değişkenlere ait özel istatistik tablosunda, her bir değişkene ait ortalama, medyan, maksimum ve minimum değer, standart hata ve gözlem sayısı bulunmaktadır.

Tablo 1: Özet İstatistik Tablosu

\begin{tabular}{lcc}
\hline & Merkezi Yönetim Bütçe Vergi Gelirleri & GSYH \\
\hline Ortalama & 16.463 & 7.250 \\
Medyan & 16.440 & 7.254 \\
Maksimum & 17.149 & 7.413 \\
Minimum & 15.622 & 7.041 \\
Standart Hata & 0.384 & 0.098 \\
Çarpıklık & -0.127 & -0.155 \\
Basıklık & 2.174 & 1.997 \\
Jarque-Bera & 3.549 & 5.231 \\
Gözlem Sayısı & 114 & 114 \\
\hline
\end{tabular}

Tablo 1'de merkezi yönetim bütçe vergi gelirleri serisinin ortalama değeri 16,463; medyan değeri ise 16,440'tır. SUE serisinin ortalama değeri 7,250; medyan değeri ise 7,254'tür. Vergi gelirleri serisinin maksimum değeri 17,149; minimum değeri ise 15,622'dir. SUE serisinin maksimum değeri 7,1413; minimum değeri ise 7,041'dir. Serilerin çarpıklık değerlerine bakıldığında vergi gelirleri değişkeninin -0,127; SUE değişkeninin -0,155 olduğu görülmektedir. Buna göre değişkenlerin sola çarpık oldukları söylenebilir. Bununla birlikte serilerin basıklık değerleri incelendiğinde vergi gelirleri serisi 2,174 değeri ile normal dağılıma göre daha dik iken, SUE serisi 1,997 değeri ile normal dağılıma göre biraz daha basıktır. Serilerin normal olmadığı ve dağılımın normal olduğu sıfır hipotezini test eden Jarque-Bera testi ele alındığında; vergi gelirleri değişkeninde 3,549 ve SUE değişkeninde 5,231 olan test istatistiği \%5 anlamlılık düzeyinde ki-kare kritik değerinden küçük olduğu için sıfır hipotezi reddedilememiştir. Bu duruma göre değişkenlerin normal dağıldığı ileri sürülebilir.

Grafik 1'de ise çalışmada kullanılan değişkenlerin seyri yer almaktadır. SUE değişkende 2009 yılında gerçekleşen düşüşün; 2008 yılında ortaya çıkan ve 2009 yılında da etkilerini sürdüren küresel finansal krizinden kaynaklandığı düşünülmektedir. 
Grafik 1: Merkezi Yönetim Bütçe Vergi Gelirleri ve Sanayi Üretim Endeksi

Merkezi Yönetim Bütçe Vergi Gelirleri

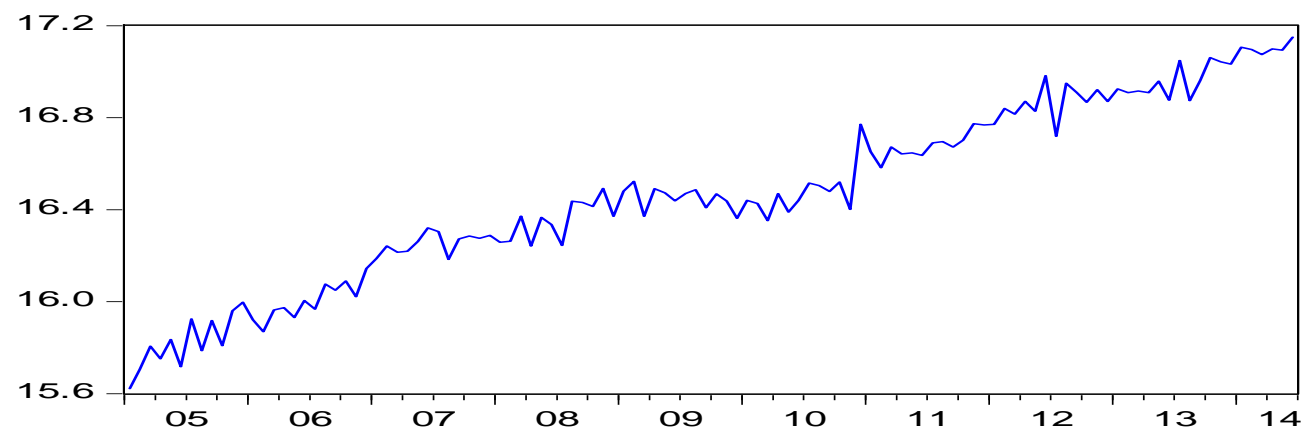

Sanayi Üretim Endeksi

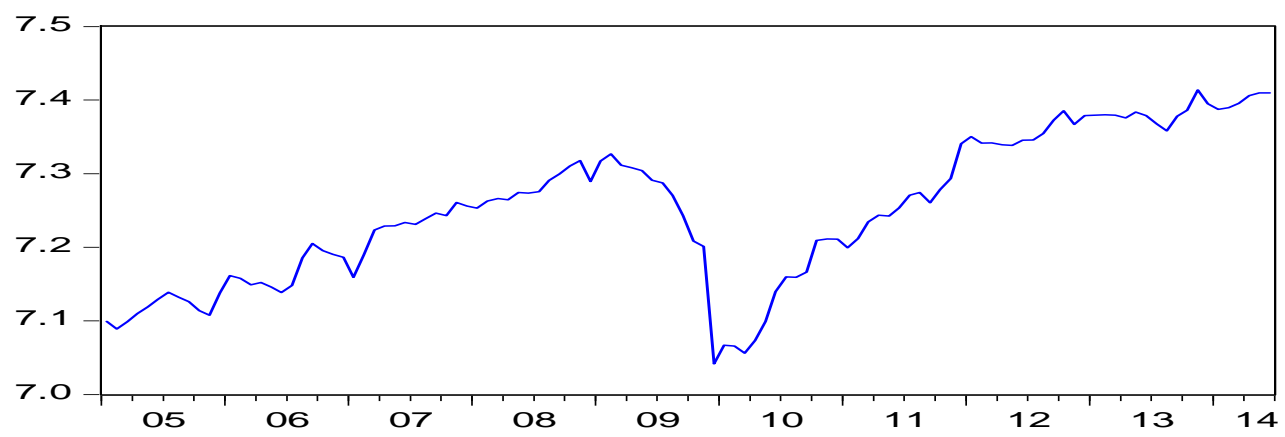

\section{AMPIRIK BULGULAR}

Çalışmada serilerin durağan olup olmadıkları Genişletilmiş Dickey-Fuller (ADF) ve PhillipsPeron (P-P) testleri ile araştırılmıştır. Hem ADF hemde P-P testlerinde sıfır hipotezinin reddedilmesi serilerin durağanlığına işaret etmektedir. Bununla birlikte P-P testinde, ADF testinden farklı olarak hata terimleri arasında seri korelasyon ve homojenlik varsayımı gerekli olmamaktadır (Tarı, 2010: 400). Tablo 2'de serilerin durağanlık test sonuçları yer almaktadır. Tablo 2'ye göre, değişkenlerin logaritmik seviyelerinde birim köke sahip olduğu ve birincil farklarında I(1), \%1 anlamlılık düzeyinde durağan oldukları görülmektedir. 
Tablo 2: Durağanlık Test Sonuçları

\begin{tabular}{|l|c|c|c|c|c|c|}
\hline & \multicolumn{3}{|c|}{ Vergi Gelirleri } & \multicolumn{3}{c|}{ SUE } \\
\hline & N & I & I ve T & N & I & I ve T \\
\hline ADF (Düzey) & 2.934 & -0.573 & -2.499 & 1.355 & -1.101 & -1.714 \\
& $(0.999)$ & $(0.870)$ & $(0.327)$ & $(0.955)$ & $(0.713)$ & $(0.738)$ \\
\hline ADF (1.Fark) & -2.725 & -14.895 & -14.854 & -9.623 & -9.740 & -9.659 \\
& $(0.000)^{*}$ & $(0.000)^{*}$ & $(0.000)^{*}$ & $(0.000)^{*}$ & $(0.000)^{*}$ & $(0.000)^{*}$ \\
\hline P-P (Düzey) & 6.889 & -1.319 & -8.626 & 1.184 & -1.289 & -2.059 \\
& $(1.000)$ & $(0.618)$ & $(0.000)^{*}$ & $(0.938)$ & $(0.623)$ & $(0.562)$ \\
\hline P-P (1. Fark) & -22.054 & -30.318 & -30.600 & -9.730 & -9.825 & -9.783 \\
& $(0.000)^{*}$ & $(0.000)^{*}$ & $(0.000)^{*}$ & $(0.000)^{*}$ & $(0.000)^{*}$ & $(0.000)^{*}$ \\
\hline
\end{tabular}

( ): marjinal anlamlılık düzeyini göstermektedir.* \%1 düzeyinde anlamlı ** \%5 düzeyinde anlamlı, I: Sabit terimli IT: sabit terimli ve trendli $\mathrm{N}$ : sabit terimsiz ve trendsiz

Birim kök testleri uygulanırken, gecikme sayısı Akaike Bilgi Kriterine (AIC) göre tespit edilmiştir. Değişkenlerin I(1) olduğu belirlendikten sonra, Johansen (1988) Eşbütünleşme testi uygulanmıştır. Johansen Eşbütünleşme test sonuçları Tablo 3'te ve Tablo 4'te yer almaktadır. Tablo 3'te iz testi sonuçları, değişkenler arasında eşbütünleşme vektör sayısını göstermektedir. Bu sonuçlara göre, \%5 anlamlılık düzeyi esas alındığında, değişkenler arasında bir tane eşbütünleşme vektörü tespit edilmiştir. Tablo 4'de yer alan maksimum öz değer testi sonuçları ise, değişkenler arasında tek bir eşbütünleşme vektörü bulunduğuna işaret etmektedir. Her iki test sonucu da merkezi yönetim bütçe vergi gelirleri ve SUE serileri arasında eşbütünleşme ilişkisi olduğuna vurgu yapmaktadır.

Tablo 3: İz Testi Sonuçları

\begin{tabular}{lllll}
\hline $\begin{array}{l}\text { Varsayılan } \\
\text { Eşbütünleme } \\
\begin{array}{l}\text { Eşitliklerinin } \\
\text { Sayısı }\end{array}\end{array}$ & Öz Değer & $\begin{array}{l}\text { İz Test } \\
\text { İstatistiği }\end{array}$ & \%5 Kritik Değer & Olasılık** \\
\hline$H_{0}: r=0 *$ & 0.202 & 30.674 & 20.261 & $(0.001)^{*}$ \\
$H_{0}: r \leq 1$ & 0.054 & 6.063 & 9.164 & $(0.189)$ \\
\hline
\end{tabular}

*\% 5 anlamlılık düzeyinde sıfır hipotezin reddedildiğini göstermektedir.

** Olasılık ( $p$-values) değerlerini göstermektedir. 
Tablo 4: Maksimum Öz Değer Testi Sonuçları

\begin{tabular}{|c|c|c|c|c|c|}
\hline $\begin{array}{l}\text { Varsayılan } \\
\text { Eşbütünleme } \\
\text { Eşitliklerinin } \\
\text { Sayısı }\end{array}$ & Öz Değer & $\begin{array}{l}\text { Maksimum Öz } \\
\text { Değer Test } \\
\text { İstatistiği }\end{array}$ & $\begin{array}{l}\% 5 \\
\text { Değer }\end{array}$ & Kritik & Olasılık** \\
\hline$H_{0}: r=0 *$ & 0.202 & 24.610 & 15.892 & & $(0.001)^{*}$ \\
\hline$H_{0}: r \leq 1$ & 0.054 & 6.063 & 9.164 & & (0.185) \\
\hline
\end{tabular}

*\% 5 anlamlılık düzeyinde sıfır hipotezin reddedildiğini göstermektedir.

** Olasılık ( $p$-values) değerlerini göstermektedir.

Değişkenler arasında eşbütünleşik bir ilişki bulunduğundan, bu değişkenler arasındaki nedensellik ilişkisi hata düzeltme yöntemi (ECM) kullanılarak analiz edilmiştir. Çalışmada ECM denklem (1) ve (2)'de gösterilmiştir. Modelde gecikme sayısı AIC bilgi kriterine göre belirlenmiştir. Modelin tahmininden bulunan nedensellik testleri ise Tablo 5 'te yer almaktadır.

$$
\Delta L \operatorname{Vergi} i_{i, t}=\gamma_{i}\left(\operatorname{InVergi} i_{i, t-1}-\beta_{i} \operatorname{InSUE} E_{i, t-1}\right)+\theta_{i, 0} \Delta \operatorname{InS} U E_{i, t}+u_{i}+\varepsilon_{i t}
$$

Tablo 5: ECM Nedensellik Test Sonuçları

\begin{tabular}{|c|c|c|c|}
\hline & \multicolumn{3}{|c|}{ Bağımsız Değişken } \\
\hline Bağımlı Değişken & $\begin{array}{l}\Delta \text { LVERGi } \\
\quad\left(\chi^{2} \text { test } i\right)\end{array}$ & $\begin{array}{l}\Delta \boldsymbol{L S U E} \\
\quad\left(\chi^{2} \text { testi }\right)\end{array}$ & $\begin{array}{c}E C T_{t-1} \\
\text { (t istatistiği) }\end{array}$ \\
\hline$\triangle L V E R G i$ & - & $\begin{array}{l}0.864[2.218] \\
(0.028)\end{array}$ & $-0.086[-2.320](0.022)$ \\
\hline$\Delta L S U E$ & 0.049 [1.218] (0.028) & - & $-0.016[-1.790](0.076)$ \\
\hline
\end{tabular}

[ ] içindeki değerler t istatistiklerini, ( ) içindeki değerler olasılık değerleri ifade etmektedir.

Hata düzeltme modelinde ilk olarak kısa dönem nedensellikleri incelenmiştir. Modelde değişkenlere ait gecikmelerin katsayılarının sıfıra eşit olduğu boş hipotezleri analiz edilmiştir. Tablo 5'te görüldüğü üzere test sonuçları istatiksel olarak anlamlıdır. Bu durum değişkenler arasında kısa dönemli nedenselliğin var olduğuna işaret etmektedir. Kısa dönemde vergi canlılığının 1'den küçük olması vergi sisteminin daha az otomatik istikrarlandırıcı olduğunu göstermektedir. ECT terimlerinin katsayıları incelendiğinde ise, istatistiksel olarak anlamlı ve negatif oldukları tespit edilmiştir. Bu da değişkenler arasında uzun dönemli nedensellik ilişkisi bulunduğunu göstermektedir. ECT terimlerinin önündeki negatif katsayılar uzun dönem dengesine ne kadar hızlı dönüldüğüne işaret etmekte ve 1 'den küçük olması beklenmektedir. Bununla birlikte hata terimi katsayısı ise uzun dönem dengesine ne kadar yaklaştığını göstermektedir. Bağımlı değişken $\Delta$ LSUE iken, hata katsayısı -0,016 değerini almıştır. 
Bu durum, uzun dönemde GSYH değişkenini yansıtan $\Delta$ LSUE değişkeninde 1 birimlik sapma olduğunda merkezi yönetim bütçe vergi gelirlerinin yaklaşık \%1'i dengeye gelmektedir. Bağımlı değişken $\triangle L V E R G \dot{I}$ olduğunda ise, hata katsayısı -0,086 olarak bulunmuştur. Bu durumda uzun dönemde $\triangle L V E R G \dot{I}$ değişkeninde 1 birimlik bir sapmada $\triangle$ LSUE yaklaşık \%8'i salınımlarla dengeye ulaşmaktadır. Bununla birlikte, uzun dönemde vergi canlılı̆ı̆ın 1 'den büyük olması, büyüme artışının mali sürdürülebilirliği olumlu etkilediği ileri sürülebilir.

\section{SONUÇ}

Küresel finansal kriz, birçok ülke önemli etkilere neden olmuştur. Bu süreçte hem gelişmiş hem de gelişmekte olan ülkeler, krizle başa çıkmak amacıyla birçok mali önlem almıştır. Bu durumda ülkelerin mali açıklarını önemli ölçüde arttırmıştır. Sürdürülebilir bir kamu maliyesi ve borçlanma politikası için ülkeler daha yüksek büyüme ve vergi gelirleri ile mali açıklarını azaltmaya çalışmaktadır. Vergi canlıığını ifade eden bu durum aslında vergi gelirlerindeki değişimin milli gelirdeki değişikliklere olan duyarlılığını göstermektedir. Vergi canlıı̆̆ı ile vergi esnekliği kavramları birbirine çok benzese de temelde farklı iki kavramdır. Vergi canlılı̆ı, vergi esnekliğinden farklı olarak idari düzenlemeleri de kapsamaktadır. Özellikle, bir ülkede vergi esneklikleri düşükse, ilave vergi gelirleri ihtiyari düzenlemelerle sağlanabiliyor demektir ki bu da vergi sisteminin canlılığının daha yüksek olduğunu göstermektedir.

Vergi canlılığı kısa ve uzun dönemde farklılıklar göstermektedir. Kısa dönemde, vergi gelirleri GSYH'dan daha fazla artarsa (kısa dönem canlılık 1 değerini aşarsa), ülkelerin vergi sisteminin iyi bir istikrarlandırıcı olduğuna işaret etmektedir. Vergi canlılığı değeri 1'den küçük olduğunda ise, vergi gelirleri GSYH'dan daha fazla durağan olduğunu göstermektedir. Bu durumda vergi gelirleri fonksiyonları daha az otomatik istikrarlandırıcıdır. Uzun dönem canlılık ise, uzun dönemde mali sürdürülebilirlik açısından ekonomik büyümenin etkisi nedeniyle büyük önem arz etmektedir. Uzun dönem canlılıkta, vergi canlılığı değeri 1 değerini aşarsa daha yüksek bir büyüme, mali dengeyi özellikle bütçe tarafını geliştirmektedir. Bu değer 1'den küçük olduğunda ise büyüme, mali dengeyi olumsuz etkilemekte ve dengeden sapmalar meydana getirmektedir (Belinga, vd., 2014: 5). Bütün bunların yanında, kamu harcamaları genelde hızlı bir şekilde artmakta ve bunların finansmanında da vergiler önem arz etmektedir. O yüzden vergi canlılı̆ının yüksek olması ve özellikle 1 'den büyük olması önemlidir. Milli gelirdeki büyüme ile vergilerin de artması kamu harcamalarının finansmanını etkilemektedir. Özellikle, eğer bir ülkede kamu hizmetlerine yoğun bir talep varsa ve mali sistemin daha istikrarlı hale gelmesi arzulanıyorsa, vergi canlılığının 1'den büyük olması istenmektedir.

Bu çalışmada Ocak 2005 - Haziran 2014 dönemini kapsayan merkezi yönetim bütçe vergi gelirleri ve SUE değişkenlerine ait aylık veriler kullanılarak, Türkiye'de vergi canlılı̆̆ı hem uzun dönem hem de kısa dönem açısından analiz edilmeye çalışılmıştır. Çalışma sonuçlarına göre; değişkenler arasında kısa dönemli nedensellik ilişkisi bulunmaktadır. Kısa dönemde vergi canlılığının 1'den küçük olması vergi sisteminin daha az otomatik istikrarlandırıcı olduğunu göstermektedir. Uzun dönemde ise, GSYH değişkenini yansıtan $\triangle$ LSUE değişkeninde 1 birimlik sapma olduğunda merkezi yönetim bütçe vergi gelirlerinin yaklaşık \%1'i dengeye gelmektedir. 
Bağımlı değişken $\triangle$ LSUE olduğunda ise, uzun dönemde $\triangle L V E R G \dot{I}$ değişkeninde 1 birimlik bir sapmada $\Delta$ LSUE yaklaşık \%8'i salınımlarla dengeye ulaşmaktadır. Diğer bir deyişle, uzun dönemde büyüme artışının mali sürdürülebilirliği olumlu etkilediği ileri sürülebilir. Bu nedenle, Türkiye'de, kısa dönemde vergi sisteminin otomatik istikrarlandırıcı olarak yeniden düzenlenmesi gerekmektedir.

\section{KAYNAKLAR}

Ahmed, Q. M. (1994). The Determinants of Tax Buoyancy: An Experience From the Developing Countries. The Pakistan Development Review. 33 (4) (Part II), 1089-1098.

Ahmed, Q.M., Mohammed, S. (2010). Determinant of Tax Buoyancy: Empirical Evidence from Developing Countries. Europen Journal of Social Sciences. 13 (3). 1-7.

Akbar, M., Ahmed Q. M. (1997). Elasticity and Buoyancy of Revenues and Expenditure of Federal Government. Pakistan Economic and Social Review. 35 (1) (Summer), 43-56.

Belinga, V., Benedek, D., Mooij R., Norregaard J. (2014). Tax Buoyancy in OECD Countries. IMF Working Paper. No:WP/14/110.

Bilquees, F. (2004). Elasticity and Buoyancy of the Tax System in Pakistan. The Pakistan Development Review. 43 (1) (Spring). 73-93.

Chowdhury, O.H., Hossain M. (1988). Elasticity and Buoyancy of Bangladesh Tax Structure. Bangladesh Institute of Development Studies, Research Report, No. 80. Bangladesh.

Durmuş, M. (2003). Ekonomik Istikrarın Sağlanması ve Kalkınmanın Finansmanı Bağlamında Maliye Politikaları, Teori ve Uygulamalarının Değerlendirilmesi. Ankara: Yaklaşım Yayınları.

Ertürk Atabey, S., Avşar, T., Bulut M. (2009). Türkiye Verilerine Göre Vergi Canlılığı ve Esnekliğinin Tahmin Edilmesi. Ekonomik Yaklaşım. 20 (71), 109-119.

Gillani, S. F. (1986). Elasticity and Buoyancy of Federal Taxes in Pakistan. The Pakistan Development Review. XXV (2) (Summer), 163-174.

Hamlet, K. K. J. (2013). Tax Buoyancy In The Eastern Carıbbean Currency Unıon and The Implications For Fiscal Consolidation: A Study Of The Commonwealth Of Dominica, St. Lucia and Antigua and Barbuda. http://www.ccmf-uwi.org/files/publications/working_papers/2013KeithKyleJHamlet.pdf (Erişim: 02.10.2014).

Haughton, J. (1998). Estimating Tax Buoyancy, Elasticity and Stability. http://pdf.usaid.gov/pdf docs/PNACE024.pdf (Erişim: 10.10.2014).

Howard, M., La Foucade A., Scott, E. (2010). Public Sector Economics for Developing Countries. Barbados: University of the West Indies Press.

Indraratna, Y., (2003). The Measurement of Tax Elasticity in Sri Lanka A Time Series Approach. Staff Studies. 33, 73-109.

Johansen, S. (1988). Statistical Analysis of Cointegrating Vectors. Journal of Economic Dynamics and Control. 12, 231-254.

Joumard, I., Andre C. (2008). Revenue Buoyancy and Its Fiscal Policy Implications. OECD Economics Department Working Papers. W. P.No.598.

Kasipillai, J., Mustafa, M. M. (2000). Bouyancy Estimates of Malaysia's Tax System: 1961-1998. Malaysian Managment Journal. 4 (1\&2), 75-87. 
Kusi, N. K. (1998). Tax Reform and Revenue Productivity in Ghana. AERC Research Paper. Number Seventy-Four, Nairobi: AERC.

Mansfield, C.Y. (1972). Elasticity and Buoyancy of a Tax System: A Method Applied to Paraguay. International Monetary Fund Staff Papers. XIX (2), 425-446

Mawia, M., Nzomoi, J. (2013). An Empirical Investigation of Tax Buoyancy in Kenya. African Journal of Business Management. 7 (40), 4233-4246.

Milwood, T. (2011). Elasticity and Buoyancy of the Jamaican Tax System. Bank of Jamaica. 1-24, http://www.boj.org.jm/uploads/pdf/papers pamphlets/papers pamphlets Elasticity and Buovancy of the Ja maican Tax System.pdf (Erişim: 25.09.2014).

Mishra, S. P. (2005). Elasticity and Buoyanacy of Sales Tax in Jharkhand. A Fiscal Policy Analysis Cell (FPAC). Project Government of Jharkhand.

Mitchell, W., Andrews, L. (1999). Tax Buoyancies in Eastern Caribbean Central Bank Member Countries. Central Bank of Barbados Working Paper. W.P. No:1999-13.

Mukarram, F. (2001). Elasticity And Buoyancy Of Major Taxes In Pakistan. Pakistan Economic and Social Review. XXXIX (1) (Summer), 75-86.

Osoro, N.E. (1993). Revenue Productivity Implications of Tax Reform in Tanzania. AERCResearch Paper. No.20, Nairobi.

Rajaraman I., Goyal R., Khundrakpam, J. K. (2005). Tax Buoyancy Estimates for Indian States. Working Paper Series. http://papers.ssrn.com/sol3/papers.cfm?abstract id=826345 (Erişim: 12.10.2008).

Rasheed, F, (2006). An Analysis of the Tax Buoyancy Rates in Pakistan. Munich Personal RePEc Archive.No. 43388, Market Forces, 3 (2).

Samwel, K. C., Isaac, M. K. (2012). Elasticity and Buoyancy of Tax Components and Tax Systems in Kenya. Research Journal of Finance and Accounting. 3 (5), 116-125.

Skeete, R., Coppin, K., Boamah, D. (2003). Elasticities and Buoyancies of the Barbados Tax System, 1977-1999. Central Bank of Barbados Working Papers.133-149

Şimşek, D. (2013). Türkiye'de Bölge Düzeyinde Vergi Esnekliği, Vergi Canlılı̆ı̆, Vergi Kapasitesi ve Vergi Gayreti.(Yayınlanmamış Yüksek Lisans Tezi). Ankara: T.C. Gazi Üniversitesi SBE Ekonometri Anabilim Dalı.

Tarı, R. (2010), Ekonometri, İzmit-Kocaeli: Umuttepe Yayıncılık.

Timsina, N. (2007). Tax Elasticity and Buoyancy in Nepal: A Revisit. NBR Economic Review.12, 9-21.

Twerefou D.F., Fumey, A., Osei-Assibey, E., Asmah, E.E. (2010). Buoyancy and Elasticity of Tax: Evidence from Ghana. Journal of Monetary and Economic Integration.10 (2), 36-70

Upender, M. (2008). Degree of Tax Bounyancy in India: An Empirical Study. International Journal of Applied Econometrics and Quantitative Studies.5 (2), 59-70.

Wawire N.H.W. (2000). Revenue Productivity Implications of Kenya's Tax System. K. Kwaa Prah ve A. G. M Ahmed (Ed.). Africa in Transformation Political Economic Issues. Addis Ababa: OSREA, 1, 99-106.

Yousuf, M., Huq, S.M.J. (2013). Elasticity and Buoyancy of Major Tax Categories: Evidence from Bangladesh and Its Policy Implication. FDRS Research Study Series. No. 03/2013.

http://evds.tcmb.gov.tr 